\title{
SÍNDROME DE DOWN E O DESENVOLVIMENTO PEDAGÓGICO
}

\author{
Elisangela Evangelista Duarte ${ }^{1}$
}

RESUMO Este artigo tem por objetivo explanar sobre a Educação Especial/Inclusão e a Síndrome de Down e seus aspectos, de forma que irá demonstrar resultados de estudos realizados em artigos, sites acadêmicos e livros, para a elaboração do referido. Após a leitura deste, o leitor compreenderá como foi a história da Educação Especial/Inclusão e seus objetivos, trazendo para o leitor uma rápida leitura e compreensão de como foi o decorrer de sua história no Brasil, quando ocorreu e as leis criadas para a inclusão de pessoas com deficiências físicas, psicológicas e o que trouxe em benefício para as pessoas com necessidades especiais, sejam elas permanentes ou não, também será citado escolas onde as pessoas com necessidades especiais em geral poderão encontrar atendimento pelo país. Durante a elaboração do trabalho foi realizada leituras em livros especializados em Síndrome de Down, que será relatado a história da Síndrome de Down, como foi descoberta, quais suas semelhanças físicas para perceber uma pessoa com a Síndrome, que não é uma doença e sim uma mudança genética, que não tem cura e não é transmitida e sim uma mutação genética chamada de Trissomia do 2I, ou síndrome de Down. Ao término do trabalho, todas as questões levantadas serão respondidas de forma clara e objetiva, levando ao leitor uma compreensão do título proposto neste trabalho como também o incentivando a procurar saber mais sobre o assunto tão importante que faz parte do nosso dia a dia.

Palavras-chave: Educação Especial. Síndrome de Down. Deficiência. Trissomia 2I. Genética. Educação.

\section{I.INTRODUÇÃO}

Muito se fala em inclusão e em pessoas com deficiências físicas e intelectuais como: Transtorno de Déficit de Atenção com Hiperatividade/Impulsividade (TDAH/I), Hiperatividade, Impulsividade, Transtorno Compulsivo (TOC), Tiques e Síndrome de Tourette, no entanto pouco se houve falar em Síndrome de Down, que também faz parte das pessoas para serem incluídas na sociedade e na escola sem que haja uma separação, como era feito no século XVIII.

\footnotetext{
I Elaboração de Material, Tutoria e Ambientes Virtuais. Universidade Cruzeiro do Sul. Psicopedagogia Institucional e Clinica, e Educação Infantil. Faculdade Venda Nova do Imigrante - FAVENI. Email:elisduarte37@hotmail.com.Currículo lattes: http://lattes.cnpq.br/3420294906955231.
} 
A Síndrome de Down é associada a um atraso intelectual, porém assim que a criança nasce já é possível verificar sua existência visivelmente, mas existem alguns exames feitos durante o pré-natal que podem sugerir um diagnóstico na alteração do feto, como aminiocentese e a biopsia do viro corial que avaliam o líquido aminiótico e a placenta, no entanto é muito agressivo.

Tendo em vista que não se conhece muito a respeito do assunto (Síndrome de Down), propomos neste trabalho trazer ao conhecimento dos leitores, como exemplo: um resumo da história do surgimento da educação especial como também será esclarecido como foi descoberto a Síndrome de Down quais as manifestações.

Para tanto, através deste artigo, iremos descobrir o que é Síndrome de Down, como as pessoas com esta anomalia cromossômicas se desenvolvem intelectualmente. Sabendo que a inclusão abrange a todas as pessoas com deficiências sejam elas físicas ou intelectuais, sejam falta de habilidades ou super dotação. A educação é um direito de todos, assim nos garante a Constituição, portanto as pessoas com Síndrome de Down fazem parte desta inclusão.

O objetivo de escrever sobre a Síndrome de Down é trazer o esclarecimento para todos através da leitura deste, trataremos de modo geral sobre a importância de conhecer sobre o assunto, conhecer suas características, saber sua origem, esperamos que ao final deste trabalho todas estas questões sejam esclarecidas.

É importante ressaltar que o trabalho foi realizado com o intuito de esclarecer dúvidas quanto a Síndrome de Down, pois sabemos que não é um assunto muito divulgado pelos acadêmicos quando se escrevem sobre Inclusão, porém a Síndrome de Down não é menos importante que as outras já citadas anteriormente, mas como o mesmo grau de importância, por isso deve ser estudada e esclarecidas dúvidas que surgirem ao decorrer da convivência do as pessoas com esta síndrome.

Para a elaboração deste artigo, foram utilizadas leituras de livros voltados para o assunto proposto, artigos relacionados a história da inclusão e da síndrome de Down, ou seja, foi realizada uma pesquisa bibliográfica para depois começar a elaboração deste trabalho. Desta forma as referências bibliográficas estarão todas disponíveis ao final deste trabalho. 


\section{DESENVOLVIMENTO}

Ao iniciarmos o trabalho vamos abordar o assunto a organização da Educação Especial, pois sabemos que se trata de um assunto relativamente novo.

Sua origem se deu por volta do século XVIII, que na época apenas as crianças com surdez e cegueiras eram atendidas, também é válido relembrar que quando as crianças nasciam com alguma deformidade eram rejeitadas e excluídas, deixadas para morrer, pois na época existia a crença que eram crianças amaldiçoadas, ou a encarnação do mal e em outros casos um milagre, se esperando que alguma dessas crianças teriam algum dom de adivinhação. Porém graças aos estudos esta concepção foi sendo excluída de forma que em 1960, começaram a surgir as Secretarias de Estado da Educação como parte para integralizar estas crianças. Sendo assim, não apenas eram atendidas as pessoas com surdez ou cegueira, mas todas que apresentavam alguma deficiência e também as que não apresentam fisicamente como as crianças superdotadas.

A Educação Especial fez com que as pessoas que apresentavam alguma deficiência física ou psicológica fossem rotuladas e separadas para que seu atendimento fosse realizado de forma que atenderia somente este público, não misturando as outras em padrão normal pela sociedade. Porém, podemos citar Veiga Neto (200I):

Ainda que os critérios de partilha normal - anormal emerjam da "pura relação do grupo consigo mesmo", as marcas da anormalidade vêm sendo procuradas, ao longo da Modernidade, em cada corpo para que, depois, a cada corpo de atribua um lugar nas intrincadas grades das classificações dos desvios, das patologias, das deficiências, das qualidades, das virtudes, dos vícios (VEIGA, 2001, p; 107).

Veiga esclarece que com a chegada da modernidade, estes alunos com deficiências sejam de desvios, virtudes ou patológicas, foram sendo deixados de lado devido a classificação que a sociedade fez. Desta forma ressaltamos que como já citado, estas crianças quando nasciam, eram vistas com outros olhos, o olhar buscado na religiosidade, pois muitos acreditavam ser castigo de Deus, outras um milagre, enfim, cada um procurava uma explicação não científica.

Porém, a medicina vem se desenvolvendo a cada ano e século, com isto através de pesquisas no século XIX, as pessoas com síndromes e apresentando alguma deficiência passaram a serem vistas pela medicina como anomalias ou patologias que existiam desde o nascimento, de forma que estas pessoas eram separadas para 
tratamento médico, o que ocorreu o paradigma da institucionalização, onde eram levados para serem tratados e isto ocorreu durante oito séculos, mais precisamente até o início do século XX.

Durante os anos de 1800 aos 1900 estas crianças quando levadas para atendimento, não haviam pretensões pedagógicas, mas somente de tratarem suas deficiências vistas como doenças mesmo não havendo cura somete paliativos, estas eram deixadas separadas por serem diferentes que o padrão da sociedade exigia.

A partir de 1980 diversas leis foram sendo elaboradas voltadas para que as pessoas com alguma deficiência sejam físicas ou psicológica sejam tratadas de forma igualitária como toda a sociedade, para isto podemos citar a primeira lei estabelecida pela Constituição Federal de 1988 (CF) no Art. 205:

Art. 205: A educação, direito de todos e dever do Estado e da família, será
promovida e incentivada com a colaboração da sociedade, visando ao pleno
desenvolvimento da pessoa, sua preparação para o exercício da cidadania e
sua qualificação para o trabalho (CF, 1988).

A Constituição garante educação para todos, verificamos no artigo citado que é um dever do Estado e da família, através desta Lei, foram surgindo outras em benefício as pessoas com deficiências, onde pode-se verificar que a própria Constituição foi a primeira lei aprovada em favor das necessidades especiais e através dela foi criado o atendimento educacional especializado para os alunos com deficiência.

Podemos fazer uma ressalva, pois quando foi elaborado o Art. 208 (CF, 1988), ainda se usava o termo portador de deficiência seja mental, sensoriais, físicas ou múltiplas, hoje já não usamos mais este termo e sim pessoas com necessidade especial, pois segundo Ferreira e Guimarães, (2003, p. 32), “(...) o sintagma necessidade especial não pode ser utilizado como sinônimo de deficiências, devido a qualquer pessoa ser submetida a alguma debilidade seja ela permanente ou temporária, oferecendo obstáculos à vida em sociedade, considerando-se sexo, fatores culturais, condições de saúde, quadros afetivo-emocionais, entre outros." Portanto, qualquer pessoa que por motivo diversos fique impossibilitado de exercer suas atividades, sejam físicas ou psicológicas são consideradas pessoas com necessidades especiais, obtendo o direito a educação como todos.

Citando a Constituição Federal de 1988 (CF) no Art. 208 inciso III, foi criado o atendimento educacional especializado (AEE): 
Art. 208 inciso III: Dispôs que o dever do Estado com a educação será efetivado mediante a garantia de atendimento educacional especializado aos portadores de deficiência, preferencialmente na rede regular de ensino.

Ou seja, a partir desta data, todos as crianças sem distinção teriam acesso à educação, porém com uma vantagem, as que apresentarem alguma deficiência, física, psicológica ou altas habilidades tem a oportunidade de se desenvolverem como qualquer outra criança em seu espaço.

É importante dizer que foi a partir da Constituição que surgiram novas leis oportunizando as pessoas com necessidades especiais e não somente aos surdos e cegos, como era por volta do século XVIII. Destacamos ainda outras leis aprovadas como a Lei de Diretrizes e Bases da Educação Nacional (LDB), que é dever do Estado garantir atendimento educacional especializado, temos também o Estatuto da Criança e do Adolescente que também assegura o atendimento a criança e adolescente portador de deficiência, ou seja, houve uma mudança em nossas leis a partir da Constituição Federal e dos esforços de pais, professores, que se dedicam a causa da deficiência para que todos sejam trados igualmente.

Já na década de 1990 tivemos então a proposta de educação para todos em (Jomtien - Tailândia 1990) e a Declaração de Salamanca (Espanha, 2004), que abriram novos caminhos para a educação na rede pública de ensino, onde estas crianças podem frequentar a rede regular de ensino, mas também tem seus momentos de reforço no Atendimento Educacional Especializado.

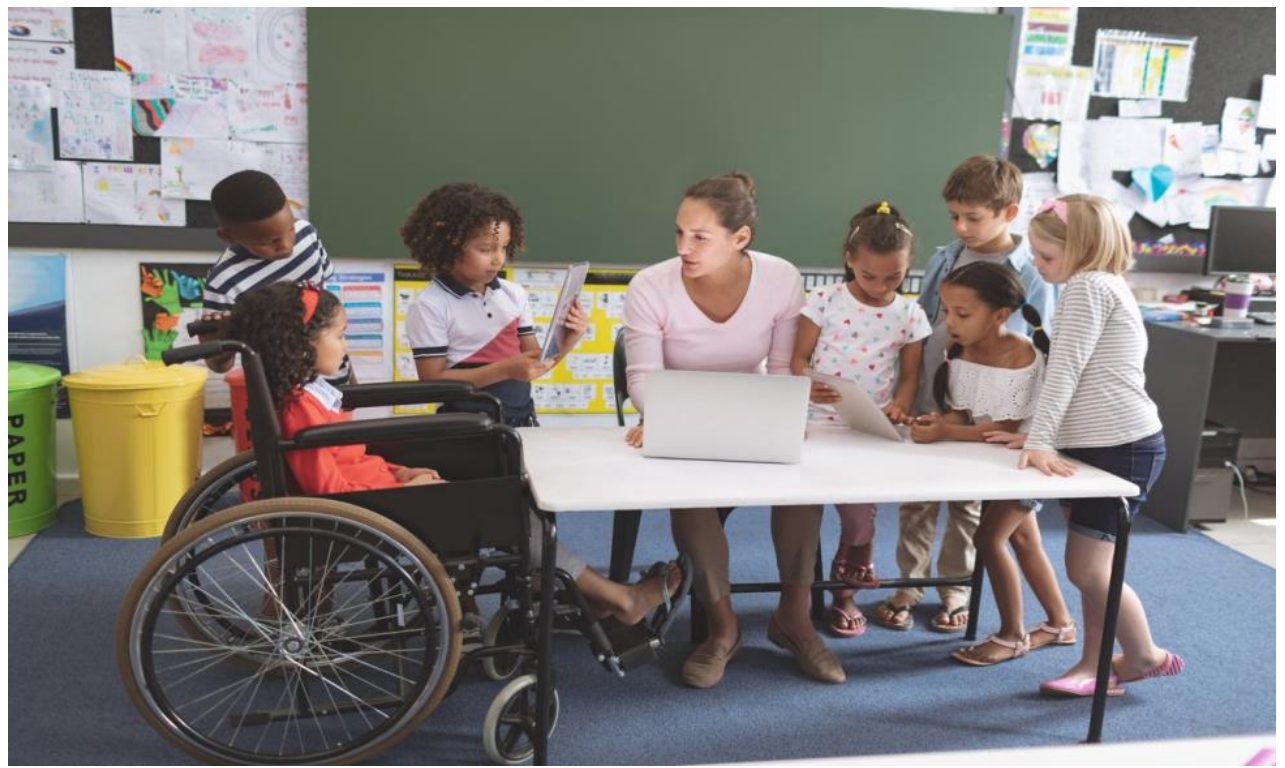

Fonte:https://novaescola.org.br/ 
Até o presente trabalho, apresentamos a caminhada a Educação Especial/ Inclusão, dentro das necessidades especiais a partir de agora abordaremos o tema Síndrome de Down.

Ao iniciarmos o estudo, vamos recorrer aos significados das palavras pela sua origem conforme o site da FioCruz:

Síndrome: conjunto de características que prejudicam de algum modo o desenvolvimento do indivíduo.

Down: Sobrenome do médico que descreveu esta síndrome John Langdon down.

Desta forma temos o termo Síndrome de Down, que foi descoberto pelo doutor John Langdon Down em I866, , ele observou que entre as crianças haviam semelhanças e atraso mental, para identificar a aparência igual ele nomeou de "mongolismo", considerando estes como seres inferiores, porém mais tarde precisamente no ano de 1958, o geneticista Jérome Lejeune, observou que exisitia um erro nos pares de cromossomos, que quando se gera uma criança seriam 46 , porém quando a criança possui a Síndrome de Down, ela possui 47 cromossos, ou seja, um cromossomo há mais, sendo assim 47 cromossomos, este há mais se ligava ao cromossomo 2I, portanto o nome de Trissomia do 2i ou Síndrome de Down como o Dr. Jérome batizou a anomalia como nome de Síndrome de Down para homenagear o Dr. John, quem verificou as primeiras semelhanças entres as crinaças e o atraso mental.

É importante ressaltar que a Síndrome de Down não é progressiva, não é contagiosa, ela é uma disfunção cromossomica, e uma deficiência mental congênita, não tem cura, porém, através do incentivo realizado por profissionais como: fonoaudiólogo, terapias, fisioterapias, psicológos e o mais importante, o contato com a família é essencial para que a pessoa com Síndrome de Down tenha uma vida saudável e normal.

Temos no Brasil, instituições que atendem crianças com Síndrome de Down, para uma melhora em sua vida, tanto pedagógica, cognitiva, familiar e com a convivência com a sociedade, são tratamentos que dependem de diversos profissionais, destacamos alguns centros para o atendimento:

Sociedade Pestalozzi do Brasil, APAE, Asdown (Goías - GO), Família Down (Belo Horizonte - MG), Down (Campo Grande - MS), Corde (Coordenadoria de 
Integração da Pessoa Portadora de Deficiência - Brasilia - DF), Associação Up-Down! (Curitiba - PR), Amigo Down (São José - SC), entre outros diversos espalhados pelo Brasil.

As crianças com Síndrome de Down apresentam algumas características esepcíficas, entre elas temos: a parte posterior da cabeça é levemente achatada (braquicefalia), cabelo liso e fino, em algumas crianças há falhas também, o rosto tem um contorno achatado, pois os ossos facial são pouco desenvolvidos, nariz pequeno, olhos semelhante ao oriental, orelhas pequenas e a borda superior da orelha é em muitos casos achatada, a boca é pequena, e no inverno os lábios constumam ficam rachados, o pescoço é de aparência larga, o abdôbem costuma ser saliente, as mãos e os pés costumas ser pequenos e grossos.
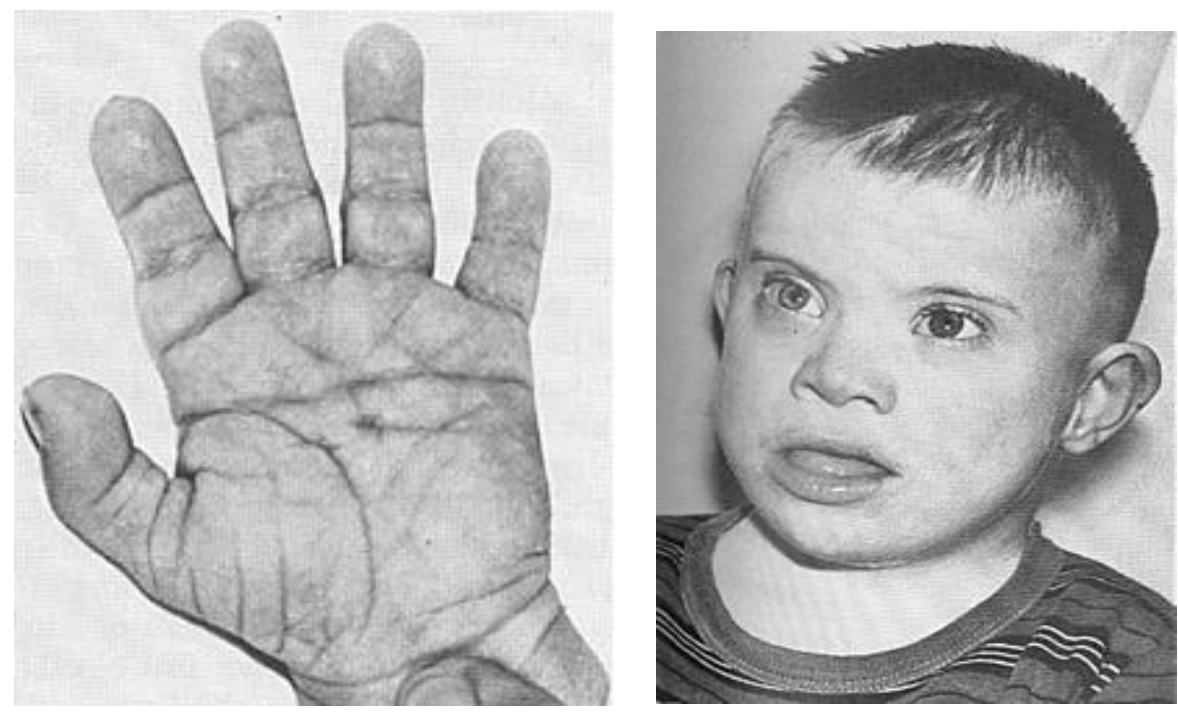

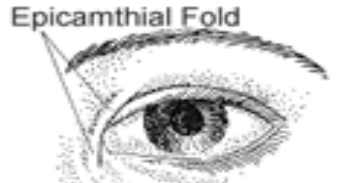

Trisomy 21

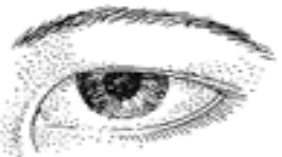

Asian

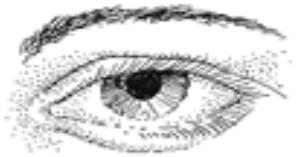

Non-Asian

Fonte: http://www.ghente.org/ciencia/genetica/down.htm

É necessário atenção, pois a criança passa a mastigar a partir dos quatro ou cinco anos, sua mastigação é mais prolongada que as outras crianças, também observa-se que os pais devem ficar atentos quanto a formação óssea e problemas de infecções são com maior frequencia, em relação a formação óssea, é necessario o acompanhamento de um ortopedista.

A família deve compreender que Síndrome de Down não tem cura, não tem remédios para amenizar a síndrome, mas deve ter acompanhamento de profissionais, 
tratando-os sempre com muito carinho, incentivando a desenvolver suas atividades, como tomar banho, ir ao banheiro sozinho, escovar os dentes, se alimentar, lembrando que tudo tem seu tempo, conforme diz Piaget que “(...) a infância é o tempo de maior criatividade na vida de um ser humano.(2001 s/p)".

Portanto, não importa se a criança não possui síndromes ou existe alguma deficiência, ela precisa ser estimulada e não obrigada a realizar suas tarefas, ela precisa de tempo para se adaptar ao meio em que convive, necessita desfrutar de seus momentos em família e na comunidade despertando sua criatividade, qanto maior a estimulação for, maior o desenvolvimento destas crianças com Síndrome de Down.

Mesmo a criança com Síndrome de down, é importante o brincar para seu desenvolvimento pedagógico e cognitivo, pois são através das brincadeiras que a criança irá aprender regras, irá transpor seus sentimentos, é necessário aos pais e educadores estarem atentos as brincadeiras não somete dentro do espaço fechado, mas também em um jardim, área com areia, onde a crianças possa correr, engatinhar ao ar livre, segundo a autora Fátima Alves (20II, p. 4I):

A criança com Síndrome de Down é capaz de alcançar um desenvolvimento motor, afetivo, social e cognitivo muito mais condizentes com o de crianças

É válido dizer que estas crianças não se prendem por muito tempo em uma atividade, principalmente se esta atividade não atrai, as pessoas que convivem com crianças com Síndrome de Down, podem proporcionar momentos para que elas se desenvolvam e ao mesmo tempo facilitar seu aprendizado, de forma que elas tendem a ficarem mais a vontade ao realizar tarefas que lhe são agradáveis, os pais e professores devem promover situações que para elas sejam um desafio de acordo com seu tempo de desenvolvimento, é necessário serem criativos na elaboração das atividades.

Ao inciarem na escola, é necessário que o professor seja paciente e tenha especialização para trabalhar com crianças com Síndrome de Down, uma vez que a criança se cansa fácil e sua concentração não tem muita durabilidade, verificamos na fala de Tunes (2003, p. 12I) onde diz:

Quando o professor tem espírito de investigação e despreza o conhecimento para compreender o conhecimento trazido pela criança,reicorporando seu saber no momento de elaborar as intervençoes que servirão para promover avanços de estruturas de que se dispõe, constituindo outras novas e mais complexas, que darão conta de resolver situações cada vez mais desafiadoras, esse professor deve ser aquele que vê, ouve e procura 
compreender o potencial de cada criança com quem trabalha. (Tunes, 2003, p. 121).

Desta forma, entendemos que o professor deve compreender os conhecimentos trazidos por estes alunos e valorizar cada um, a inteligência da criança com Síndrome de Down, é despertada através do incentivo de cada uma, como também depende da convivência em família, se é ou não estimuladas, isso deve partir dos pais e chega até a escola, não é possível fazer comparações entre as crianças com desenvolvimento ditos normais e entre as crianças com Síndrome de Down, pois cada criança reage de uma forma específica, capacidade de guardar informações difere de uma para outra, não importando se tem ou não alguma deficiência, na verdade o que realmente importa é que a criança deve estar a vontade para que seu desenvolvimento tanto pedagógico quanto, emocional, cognitivo seja completo no decorrer dos anos. Assim, o que se deve fazer na escola, é o professor conhecer bem a família da criança, seus hábitos, maninas, debilidades e trabalhar com o que a crianças já compreende, de acordo com sua idade e até de adquirir uma formação profissional.

Para falarmos sobre o desenvolvimento cognitivo, recorremos a Piaget (I952), que retrata sobre a Psicogênege do Desenvolvimento Cognitivo, ele explica que o ser humano necessita de adaptação psicológica, ou seja, uma busca em compreender e explicar o mundo em que vive.

Piaget (1975) nos informa que exitem estágios onde o ser humano passa para ser construído seu desenvolvimento cognitivo e pedagógico, passo a passo, assim temos os períodos de desenvolvimento humano:

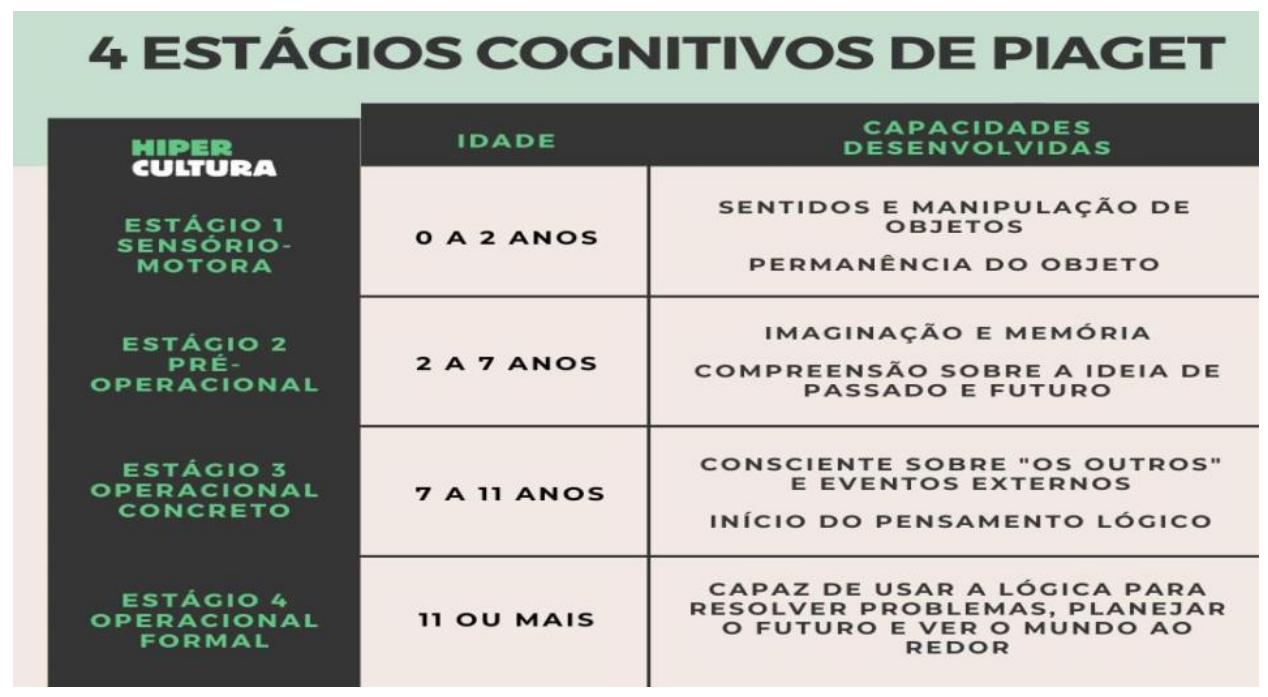

Fonte: https://www.hipercultura.com/teoria-de-piaget/ 
Portanto, conseguimos compreender cada estágio do desenvolvimento do ser humano e por outro lado temos a autora Fátima Alves(20II) que realizou em seus estudos descrito no livro "Para entender a Síndrome de Down", um paralelo com o quadro de desenvolvimento de Piaget(1975) para crianças com Síndrome de Down:

- Do nascimento até os cinco ou seis meses, a criança está nos estágios I e 2 e ainda não sabe brincar com os objetos.

- Dos 12 aos 24 meses, a criança está no estágio 4 e perceber que um objeto pode ser posto dentro de outro; sabe juntar objetos e colocar dentro de alguma coisa.

- Dos 24 meses aos 03 anos, a criança começa a combinar os objetos juntando os parecidos, distribuindo-os em coleções, o que mostra que ela está no estágio 5 .

- Depois dos 03 anos, ela entra no estágio 6e, além de colecionar os objetos semelhantes, faz correspondências, agrupa-os, dividindo-os como grandes e pequenos.

É evidente as diferenças encontradas no paralelo dos dois quadros, o que não quer dizer que a criança com síndrome de Down não possa ter uma vida com qualidade e possibilidades para seu desenvolvimento. A autora Claudia Werneck (I993), no orienta que “(...) a maior limitação para que os portadores de Síndrome de Down se tornem adultos integrados, produtivos, felizes e independentes não é imposta pela genética, mas sim pela sociedade".

Diante desta fala entendemos que a pessoa com Síndrome de Down pode e deve ter uma vida saudável e normal como qualquer outra pessoa.

\section{CONCLUSÃO}

Chegamos ao término do trabalho com os esclarecimentos como surgiu a Educação Especial/Inclusão, observamos que durante seu percurso houveram diversas alterações, início somente alcançava algumas pessoas com deficiências e no decorrer de sua história foi sendo transformada e agregada novas leis para garantir os direitos de pessoas com deficiências, sejam elas intelectuais, físicas ou com altas habilidades.

Conhecemos um pouco da história da Síndrome de Down, como ela surgiu e que na verdade foi o geneticista Dr. Jêrome quem descobriu o cromossomo há mais 
tornando assim a Trissomia do 2r ou mais conhecida como Síndrome de Down, que levou este nome em homenagem ao Dr. John Langdon Down.

Compreendemos como a pessoa som Síndrome de Down quais são as semelhanças físicas que elas apresentam e que ela pode ter uma qualidade de vida através de incentivos e estímulos acompanhados por profissionais que atuam nesta área, também indicamos algumas redes onde no Brasil estas crianças são atendidas para acompanhamento médico e pedagógico.

Ao concluir este trabalho acreditamos que as questões citadas anteriormente todas foram esclarecidas, finalizamos com uma foto do arquivo de família, uma criança com Síndrome de Down com dois anos de idade, assim temos a esperança que no futuro todas as crianças sejam elas com Síndrome de Down ou outras debilidades, sejam tratadas de forma igualitária pela sociedade, que não há a exclusão, pois todas tem o mesmo direito. Só depende de nós!

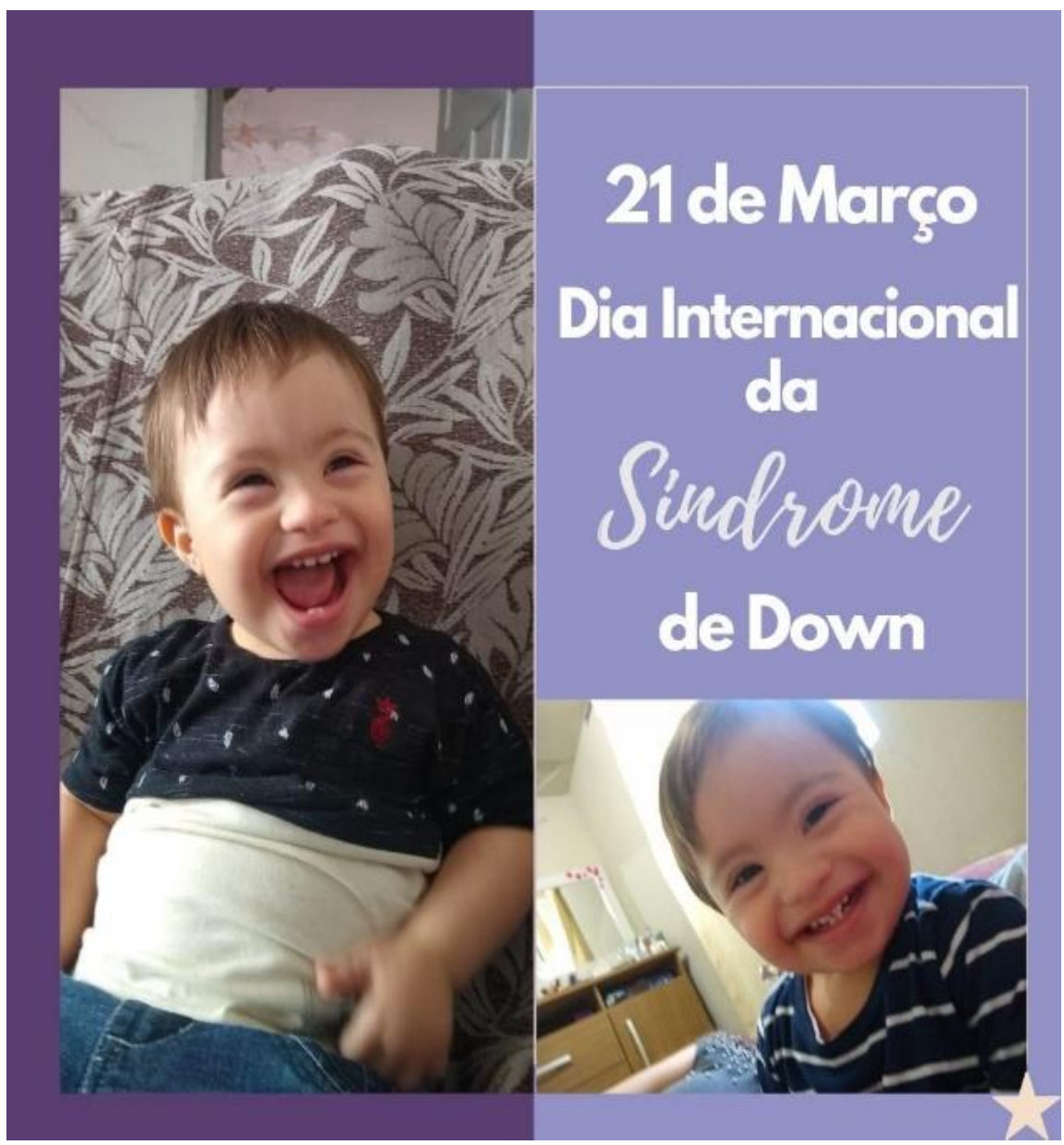

Fonte: Arquivo de Família 


\section{REFERÊNCIAS}

ALVES, Fátima. Para entender Síndrome de Down. Rio de Janeiro. 2 Ed. - Wak Ed., 2011 .

BRASIL. Constituição (1988). Constituição da República Federativa do Brasil, 1988. Brasília: Senado Federal, Centro Gráfico, 1988.

BRASIL. Lei no9,394, de 20 de dezembro de 1996. Estabelece as diretrizes e bases da educação nacional. Diário Oficial da União, Brasília, DF, v. I34, n, 248, 23 de dez. 1996. Seção I p. 27834-2784I.

BRASIL. Lei no 8.069, de 13 de julho de 1990. Dispõe sobre o Estatuto da Criança e do Adolescente e dá outras providências. Diário Oficial [da] República Federativa do Brasil, Brasília, DF, i6 jul. I990. Disponível em: $\langle$ http://www.planalto.gov.br/ccivil_o3/LEIS/L8069.htm\#art266〉. Acesso em: 13/03/2021.

Declaração Mundial sobre Educação para Todos. Conferência de Jomtien 1990. Disponível em: https://www.unicef.org/brazil/declaracao-mundialsobre-educacao-para-todos-conferencia-de-jomtien-I990. Acesso em 13/o3/202I.

Declaração de Salamanca e Linha de Ação sobre Necessidades Educativas Especiais. Brasília: Coordenadoria Nacional para Integração da Pessoa Portadora de Deficiência, 1994. Disponível em: http://portal.mec.gov.br/seesp/arquivos/pdf/serie3.pdf. Acesso em I3/03/2021.

FERREIRA, Maria Elisa Caputo; GUIMARÃES, Marly. Educação inclusiva. Rio de Janeiro: DP\&A, 2003.

Projeto Escola Viva. Necessidades Educacionais Especiais dos Alunos. Brasilia, 2005. Disponível em:http://portal.mec.gov.br/seesp/ pdf/visaohistorica.pdf ACESSO EM I2/03/2021.

PIAGET, J. Criatividade. In: VASCONCELOS, M. S. (Org.). Criatividade: psicologia, educação e conhecimento do novo. São Paulo: Moderna, 2001.

PIAGET,, J. Seis estudos de Psicologia. Trad. de Maria Alice Magalhães DÁmorim, Paulo Sérgio Lima silva. Rio de Janeiro, Forense Universitária, 1975.

Síndrome de Down: disponível em: http://www.fiocruz.br/biosseguranca/Bis/infantil/sindromedown.htm\#: :text=S\%

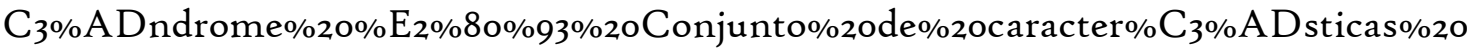
que,que\%20a\%2opossuem\%2ode\%2otriss\%C3\%B4micos\%20. Acesso em: 14/03/2021

Síndrome de Down: Aspectos, Históricos, Biológicos e Sociais: Disponível em:https://files.cercomp.ufg.br/weby/up/8o/o/TCEM2or4BiologiaCeciliaSilvaMA 
ta.pdf? $145467 \% \mathrm{~B}_{4}$ me\%2oLejeune\%2overificou\%2oque\%2,oem\%2ocertos,e\%20em\%20a mbos\%20os\%2opais. Acesso em I4/o3/2021

TUNES, E. Cadê a Síndrome de Down que está aqui? O gato comeu...: Programa da Lurdinha. Campinas, SP: Ed. Autores Associados, 2003. ??

WERNECK, C. Muito prazer, eu existo: um livro sobre as pessoas com síndrome de Down. Rio de Janeiro: Ed. WVA, 2ª ed. ,1993 